\title{
INDICES OF THE STATE OF NUTRITION IN CHILDREN *
}

\author{
H. GRAY M.D., AND G. H. EDMANDS \\ BOSTON
}

The Problem: What is the normal state of nutrition for this child?

The doctor's answer too often has depended on the shifting sands of subjective impressions. In the search for a solid objective standard, we have hunted through a quantity of books and articles on diseases of nutrition, metabolism, obesity and the like, many of them by writers of established reputation, but have been surprised and disappointed at the complete omission of a standard of nutrition in many of these monographs, and among the rest at the un-uniform "standards." This lack of uniformity not only catches the eye during casual perusal but on comparison becomes astounding, as we have pointed out in previous papers on body weight. ${ }^{1}$ We have also reported the case of a healthy child, aged 4 years, whose weight agreed exactly with one standard but differed from another standard by 31 per cent.

Averages of weights and heights are the time-honored basis of the different standards. But as objections have been made to the use of averages, a few remarks may be in place. It is admitted that many normal persons differ considerably from the avèrages; for example, that the normal weight (for a given age, standing height, sitting height, or other measurement) is not a line but a zone. At the same time, we feel with Schwiening ${ }^{2}$ and others that averages are at present the best available criteria; that is, that they are neither unduly high, owing to a peculiar number of heavy children among those observed, nor unduly low, owing to a peculiar number of thin children. This, as a general rule, seems true, although we have tried in this paper to give greater precision by utilizing boys of so-called upper strata of society, and, further, excluding those boys who seemed subnormal. In other

* Received for publication, Oct. 26, 1921.

1. Gray, H., and Gray, K. M.: Boston M. \& S. J. 177:894 (Dec. 27) 1917.

Gray, H., and Mayall, J. F.: Arch. Int. Med. 26:133 (Aug.) 1920.

Gray, H., and Allen, F. B.: Boston M. \& S. J. 184:334 (March 31) 1921.

Gray H., and Root, H. F.: Boston M. \& S. J. 184:439 (April 28) 1921.

Gray, H., and Root, H. F.: Boston M. \& S. J. 185:28 (July 7) 1921.

Gray, H.: M. Clinics N. America, 4:1899 (May) 1921.

Gray H., and Jacomb, W. J.: Am. J. Dis. Child. 22:259 (Sept.) 1921.

Gray, H.: Am. J. Dis. Child. 22:272 (Sept.) 1921.

Gray, H., and Walker, A. M.: Am. J. Physical Anthropology, 4:231 (July-Sept.) 1921. 1914.

2. Schwiening, H.: Deutsch. med. Wchnschr. 40:498, 556 (March 5 and 12) 
words, we think that our averages are adequate for the present purpose, which is to ascertain by what method one may estimate the nutrition of a child with the least error.

Once some standard has been proven superior, it will certainly be desirable to determine the "distribution"; that is, the number of children above and below the average, and the extent to which the extreme normals are found to differ from the average.

This distribution has already been reported by various observers for the weights of persons of given statures, but this ratio $W: H$ is being superseded by the relationship of weight to other anthropometric measurements (stem-length, chest-girth), as among others we have. been interested in reporting. ${ }^{1}$

Similarly, from our viewpoint, it will be desirable to determine the average and distribution (1) for each age of stem-lengths and chestgirths; (2) for each stem-length of weights and of chest girths, and (3) for each chest-girth of weights.

\section{SYNOPSIS OF STUDIES ON INDICES OF NUTRITION}

Other methods have previously been surveyed by us in several places, hence attention will be confined to an attempt to summarize more recent methods. Most of these deal primarily with weight in relation to age or to some measurement, while a few deal with measurements, but not weights, in relation to age.

Perhaps the simplest way of guessing the state of nutrition is by the Dunfermline scale, by which a child is eyed and ticketed I, II, III or IV. Such an estimation must be granted a certain merit when made by an experienced observer, but crudeness of this kind is neither satisfactory in theory, nor in practice has it been justified by those who have reported comparisons of it with more exact systems.

Oppenheimer ${ }^{3}$ judged the state of nutrition only after making in infants the following elaborate notations: age, weight, height $(\mathrm{H})$, and the circumferences of head, chest (C), belly, right upper arm, left forearm, right thigh, and left calf. In order to simplify these to a working basis, he experimented with the formula $C x$ upper-arm-girth divided by $\mathrm{H}$. This "measure of nutrition" he found for well nourished infants generally from 8 to 9 , but with such marked exceptions that he felt obliged to try another formula. This he called the "Nutrition quotient": $100 \times$ upper-arm-girth divided by $\mathrm{C}$, and he found it to be from 30 to 31 , but again with extraordinary extremes. However, he ventured his judgment after examining these two indices. This seems both too complex and too subjective.

3. Oppenheimer, K. : Deutsch. med. Wchnschr. 35:1835 (Oct. 21) 1909. 
Oeder ${ }^{4}$ has studied nutritional indices in adults, in a series of papers from 1908 to $1920 .^{4}$ He lays the greatest emphasis on the relation which he believes to exist between the body-weight and what he calls the proportional-length. This proportional length is twice the distance from the top of the skull to the middle of the pubic bone. This contention is not supported by evidence which we recently published. ${ }^{1}$

Oeder also reported studies of the muscular development by measuring the upper arm-girth with the biceps contracted and relaxed, then analyzing the difference between the two measurements, but found this no good.

More worthy of consideration are the signs of the normal state of nutrition which Oeder has laid down: (1) Invisibility of the intercostal spaces near the sternum; (2) invisibility of the intertendon spaces on the backs of the hands; (3) equal level of abdomen and chest when supine; (4) abdominal fat layer of from 2 to $3 \mathrm{~cm}$. at the base of a fold picked up parallel to the body axis and just to the right of the navel (Indexstelle; Vergleichstelle), and measured to the nearest quarter centimeter with ordinary obstetric or special calipers, one tip of which is placed about $1 \mathrm{~cm}$. to the right of the navel. For this "Fettpolstermessung" he found nearly the same figures from 2 to $3 \mathrm{~cm}$. (average for men $2.5 \mathrm{~cm}$., for women $2.7 \mathrm{~cm}$.) in normals of both sexes and all adult ages (he studied men of 24 years and over, womer 21 and over). While granting that the distribution of the fatty layer varies slightly in the sexes and at different ages, he found the variation so small that "the normal state of nutrition generally can be defined fairly accurately for any subject by the same measurement, the 'Indexfettpolsterdicke' alone." The nutrition he would often consider normal, even in the absence of one or the other of these signs, most frequently the second.

Of these signs the most objective is clearly the fat-layer. With regard to it Peiser ${ }^{5}$ said :

The older doctors have always, in order to orient themselves on the state of nutrition of a child, picked up and felt a fold of skin. They chose, as a rule, the skin of the cheek. The children, to be sure, have generally regarded this as a joke. . . . Czerny has constantly pointed out that .. . the consideration of the lower half of the body is more important than the upper. . . The first to carry out systematic measurements of the fat-layer was Oeder in adults.

4. Oeder, G.: Deutsch. med. Wchnschr. 35:1079 (June 11) 1908; Ztschr. f. Versicherungsmedizin, 1909 (not seen); Med. Klin. 4:461 (March 28) 1909; Id'. 5:1225 (Aug. 15) 1909; Id. 6:657 (April 24) 1910; Fortschr. d. Med. 29:96: (Oct. 12) 1911; Deutsch. med. Wchnschr. 40:917 (April 30) 1914; Berl. klin. Wchnschr. 52:433 (April 26) 466 (May 10) 1915; Berl. klin. Wchnschr. 52: 1086 (Oct. 18) 1915; Deutsch. med. Wchnschr. 42:1073 (Aug. 31) 1916; Ztschr. f. exper. Path. 21:263 (Aug. 26) 1920; Münch. med. Wchnschr. 67:1368 (Nov. 19) 1920.

5. Peiser, J.: Jahrb. f. Kinderh. 95:195, 1921. 
With careful measurements at the same place Oeder seldom found a greater difference than $0.25 \mathrm{~cm}$. This, compared with his average $2.75 \mathrm{~cm}$. for 607 normal adults (his 936 thin people averaged $1.1 \mathrm{~cm}$. and his 377 fat people $4.4 \mathrm{~cm}$.), we notice to constitute an error of about 9 per cent. True, he states this as his outside error, but he admits that the technic requires the greatest care and considerable practice. One wonders how large the error would be in the hands of the busy practitioner or school examiner.

In children, Oeder's abdominal fat-layer has received attention from Neumann ${ }^{6}$ and Batkin. ${ }^{7}$ Their results support the hope that the method may be proved useful, but afford only partial proof in that their results, as noted by Peiser, fail to coincide. For instance, we see that Neumann found for boys from 4 to 13 years an average abdominal fat-layer of $5 \mathrm{~mm}$., whereas Batkin found for boys from 5 to 10 years an average of $13 \mathrm{~mm}$., or more than twice as great.

From these figures it is apparent that children have an abdominal fat layer only one quarter or one half that of adults.

Rohrer ${ }^{8}$ proposed his index of the Körperfülle as a measure of the state of nutrition. This index $100 \mathrm{~W} / \mathrm{H}^{3}$ has been regarded by Oeder as theoretically no better than the nearly identical and often rejected formulae of Buffon $^{9}\left(\mathrm{~W} / \mathrm{H}^{3}\right)$ and of Livi ${ }^{10} 100 \sqrt[3]{\frac{3}{\mathrm{H}^{3}}}$. In practice, too, apart from its wide use as a standard for the selection of undernourished German children to receive the food so generously given by the Quakers, Rohrer's index seems to have been denounced all the way from dubious to "very bad," by Matusiewicz,"11 Bachauer and Lampart, ${ }^{12}$ Davenport, ${ }^{13}$ Hamburger and Jellenigg, ${ }^{14}$ Schlesinger, ${ }^{15}$ Wagner, ${ }^{16}$ Bokofzer, ${ }^{17}$ Pfaundler, ${ }^{18}$ Kaup ${ }^{19}$ and Huth ${ }^{20}$. Less adverse are Bardeen ${ }^{21}$ and Berliner. ${ }^{22}$

6. Neumann, H.: Jahrb. f. Kinderh. 75:481, 1912.

7. Batkin, S.: Jahrb. f. Kinderh. 82:103, 1915.

8. Rohrer, F.: Corr.-B1. d. Deutsch. Gesell. f. Anthropologie 39:5 (Jan.Feb.) 1908; Münch. med. Wchnschr. 68:580 (May 13) 1921; Münch. med. Wchnschr. 68:850 (July 8) 1921.

9. Buffon, G. L. L. de: Oeuvres completes, Bruxelles, 1833.

10. Livi, R.: Arch. ital. de Biol. 32:299, 1899, rev. in Hoffman: Schmidt's Jahrbücher 266:221, 1900.

11. Matusiewicz: Inaug.-Diss., München, 1914.

12. Bachauer and Lampart: Münch. med. Wchnschr., 67:1296 (Nov. 5) 1920.

13. Davenport, C. B.: Am. J. Physical Anthropology, 3:467 (Oct.-Dec.) 1920.

14. Hamburger, F., and Jellenigg, K.: Wien. klin. Wchnschr. 33:1131 (Dec. 23) 1920.

15. Schlesinger, E.: Münch. med. Wchnschr. 67:1523 (Dec. 31) 1920.

16. Wagner, R.: Ztschr, f. Kinderh. 28:38 (Feb. 14) 1921.

17. Bokofzer: Münch. med. Wchnschr. 47:593 (May 26) 1921.

18. Pfaundler, M.: Münch. med. Wchnschr. 68:974 (Aug. 5) 1921.

19. Kaup, J.: Münch. med. Wchnschr. 68:976 (Aug. 5) 1921.

20. Huth, A.: Ztschr. f. Kinderh. 30:39 (Aug. 19) 1921.

21. Bardeen, C. R.: Carnegie Pub. No. 272, Washington, D. C., 1920, p. 483.

22. Berliner, M.: Berl. klin. Wehnschr. 58:58 (Jan. 17) 1921. 
Without referring to these unfriendly comments, Rohrer stated that possibly one should use three indices:

I $1=$ Height,

I $2=$ Some body width, such as the shoulder or pelvic breadth (intercristal diameter),

I $3=$ Some body depth measurement, such as the sagittal thoracic or the average of this and the sagittal pelvic diameter.

Similar diameters have been suggested before, without result, and indeed complexity would seem to bar this method.

Sperk ${ }^{23}$ measured (1) as an index of musculature: the girths of the neck, chest and upper arm; (2) as an index of fat: the circumferentia minima abdominalis of Lenhoff, because he found this to show individual differences better than Oeder's method; and finally, (3) as a measure of the bones: he used the girth of the lower end of the fore arm. The utility of these measurements remains to be proved.

Huth $^{20}$ measured thirty-one pupils of an average age of about 11 years: H, W, C, shoulder breadth, upper arm girth, waist girth, and thigh. His utilization of these measurements does not seem helpful at present. His statistical analysis, however, deserves attention, in view of the recent papers by Pearl, ${ }^{24}$ Harris and Benedict, ${ }^{25}$ Dreyer and Walker, ${ }^{26}$ Kilgore ${ }^{27}$ and Feldman, ${ }^{28}$ emphasizing the vast latent possibilities of medical progress by statistics made by the improved biometric methods. Owing, however, to the present unfamiliarity of medical men with biometric complexities, we venture to think our method for testing standards as given below is simpler and we hope adequate.

Huth tried to solve the question "Are the body measurements a function of the state of nutrition or not?" by the use of the coefficient of correlation $(r)$, which he calculated for seven different standards.

His conclusion was that since in all these $r$ was negative (from -0.02 to -0.15 ), there existed no correlation between state of nutrition and body measurement indices, and, therefore, no functional connection. With this inference we agree, but think he is outrunning his evidence when he goes on to say: "hence it is not permissible to try to establish the state of nutrition with the help of body measurement indices. . . . We ought to get a correlation of at least +0.6 in order to regard an index as half way reliable."

23. Sperk, B.: Wien. klin. Wchnschr. 34:210 (May 5) 1921; Abstr. Boston M. \& S. J. 185:66 (July 14) 1921.

24. Pearl, R.: Arch. Int. Med. $24: 398$ (Oct.) 1919; Johns Hopkins Hosp. Bull. 32:184 (June) 1921.

25. Harris, J. A., and Benedict, F. G.: Carnegie Publication No. 279, Washington, D. C., 1919, pp. 1, 9 and ff.

26. Dreyer, G., and Walker, E. W. A.: Contributions to Medical and Biological Research (Osler), N. Y. 1:40, 1919.

27. Kilgore, E. S.: J. A. M. A. 75:86 (July 10) 1920.

28. Feldman, W. M.: Brit. J. Child. Dis. 17:171 (Oct.-Dec.) 1920. 
OTHER STANDARDS SELECTED FOR STUDY HERE

Besides the methods just reviewed, there are three others which have appealed to us as the most promising in the literature: Von Pirquet's, ${ }^{29}$ Dryer and Hanson's, ${ }^{30}$ and the Ideal size and weight tables recently reported by us. ${ }^{1}$

Methods for predicting the normal weight for a given person from one or more of his physical measurements have been proposed from time to time; but have surprisingly seldom (apart from Huth's valuable contribution) been tested simultaneously on the same series of healthy children. Even a brief test will reveal astoundingly diverse weights for one and the same subject, according to the formula applied. The conclusion seemed fair therefore that more study was necessary to determine which of these competing "standards" was most worthy of the name, and also to indicate if possible which physical measurements are in future most worth recording.

The results so far, though tedious, are encouraging. Dreyer and Hanson's new book of tables leads the field, judging by evidence which we have recently assembled regarding adult men and a few boys of preschool and school age. ${ }^{1}$ Indeed, one is almost swayed by enthusiasm when one has been able to show a mother intelligent enough to be worried because her child seemed 30 per cent. too fat by such an approved standard as Holt's, ${ }^{31}$ that according to Dreyer and Hanson's prediction the child weighed within 1 per cent. of what he should.

It may be convenient to present here the more practical details of these three methods, while referring any interested reader to our fuller

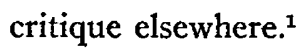

The Ideal tables just mentioned were arrived at in the following manner. In routine examinations of well-to-do and healthy boys in country day and boarding schools, we had been impressed by the unfitness of the usual pediatric tables for height and chest-girth in relation to age, and for weight in relation to height. This was easily explained by the fact that the usual tables had been constructed from observations on public school children, and that too without exclusion of those children who were clinically below par. New and different standards, constructed from observations on the cultured class of boys, seemed to us indispensable, and we, therefore, published the averages of our observations on 380 such boys, aged from 6 to 20 years. We

29. Pirquet, C.: Ztschr. f. Kinderh. 6:256, 1913; 14:211, 1916; also reprinted in his book "System̀ der Ernährung," Berlin, 1919, 2:284; Ztschr. f. Kinderh. 18:220, 1918; Osterreichischen Rundschau, 63:10, 1920 reprint.

30. Dreyer, G., and Hanson, G. F.: The Assessment of Physical Fitness, London, 1920; reprinted by Hoeber, N. Y., 1921.

31. Holt, L. E.: Diseases of Infancy and Childhood, New York, Ed. 8, 1919 
hoped, of course, that this way of attack would be followed by others who could command larger material, accumulate vaster data, and on that basis construct less tentative tables.

Our Ideal Tables showed the average height for age, chest-girth for age, weight for age, and finally what had received scant notice but seemed to us useful, weight for chest-girth. This last standard, chestgirth, we wish to insist on, as very probably affording the most valuable of all so far suggested, provided a single measurement be desired. For an example, see Table 1, last column, fourth row up, 2 per cent.

Pirquet judged weight in relation to sitting height by means of his index which he first called the Gilidusi. This he then amended to the Gelidusi, or cube root of ten times the weight in grams divided by the sitting height in centimeters :

$$
\frac{\sqrt[3]{10 \bar{W}}}{\mathrm{Si}}=100
$$

Still later he proposed a new name for the same index: Pelidisi, compounded of the initials of Latin (perhaps for foreign consumption) instead of German words. His ideas have been discussed by Bernstein, ${ }^{32}$ Von Gröer, ${ }^{33}$ Schick ${ }^{34}$ and Faber. ${ }^{35}$ As the latter has pointed out, there are "certain minor inaccuracies and disagreements" in Pirquet's writings. The most important of these inaccuracies seems to be in his formula : ${ }^{36} 100(10 \times \mathrm{W} \text { in g. })^{2 / 3} \div \mathrm{Si}=100$.

If, now, this two-thirds power be considered a misprint for onethird, the formula will read: $100 \sqrt[3]{10 \times \mathrm{W} \text { in } \mathrm{g}}$. / $\mathrm{Si}=100$, in which case the Pelidisi will come out approximately a hundred instead of yielding a decimal (as is given by the first sample printed above, according to Pirquet's 1916 article, p. 216). This proposed correction represents correctly, we believe, Pirquet's theory. His formula has found so much favor in feeding the children of Austria that it must be tested.

It would seem that the fundamental idea underlying the Pelidisi index might be stated in a style more like the weight prediction formulae used by others. For example, instead of his conclusions that Index Pelidisi $\sqrt[3]{10 \times \text { weight }} \div$ sitting height) in muscular adults and plump infants averages 100 , and in grown children 94 , it seems more practical to say that for (1) adults: W (in g.) $=\mathrm{Si}^{3}$ (in $\mathrm{cm}$.) $\div 10$, and for (2) growing children: W (in g.) $=(0.94 \mathrm{Si})^{3} / 10$.

32. Bernstein, F.: Ztschr. f. Kinderh. 16:78, 1917.

33. Von Gröer, F.: Ztschr. f. Kinderh. 18:287, 1918 (Sonderheft).

34. Schick, B.: Das Pirquetsche System der Ernährung, Berlin, Ed. 2, 1919, p. 27.

35. Faber, H. K. : Am. J. Dis. Child. 19:478 (June) 1920; See also his chart showing Sitting Height-Weight Nutritional Index of Von Pirquet (Pelidisi), reproduced and distributed by San Francisco Tuberculosis Assn., 1921.

36. Pirquet: System der Ernährung, 2:287, 1919. 
Hamburger and Jellenigg said that a cursory valuation of their cases indicated that the Pelidisi method yields an error of hardly less than 40 per cent., and we have reported ${ }^{1}$ two cases in boys of 4 and 3 years, respectively, in which the error of the Pelidisi was 31 and 22 per cent., respectively. The error in our present series of 114 school boys was 21.5 per cent.

Dreyer realized, as had Bornhardt ${ }^{37}$ but practically nobody else before him, that in predicting weight body-length alone was inadequate. Like the Russian military surgeon, he made simultaneous use of the chest measurement, but "substituted stem length for stature, and constructed his formula in an entirely different fashion.

Dreyer and Hanson then used the stem length of Walker, ${ }^{38}$ a. measurement generally about 3 per cent. smaller than the sitting height but having the advantage that it can be determined with more accuracy and constancy.

\section{TECHNIC}

The length $(\lambda)$ is measured by seating the subject on the floor or on a low table (not a chair) with the back against the wall. Care is taken to see that the sacrum is in contact with the wall, and the legs somewhat drawn up so that the individual sits fairly on his ischial tuberosities. Under these conditions the height of the top of the head gives a true measurement of the length of the body, and one which is constant and incapable of variation by the subject. If a chair or other form of seat be employed in taking this measurement the individual can by "sitting low" or "sitting high" produce at will a variation of as much as 3 per cent. or more. But, since a subject conscious that he is being measured for height tends naturally to produce a full measurement, it will be found that he intentionally "sits up," straightening the spine, tilting the pelvis forward, and rests on the contracted muscles of the thighs and buttocks instead of on his ischial tuberosities. The apparent length-"sitting height," as it has been termed-is thus increased by between 2 and 3 per cent. above the measurement taken in the manner already described. Accordingly measurements taken on a seat require to be corrected down appropriately before they can be treated as comparable with the measurement of body-length in infants or animals. (Walker ${ }^{88}$ ).

The subject places the backs of the fingers on the platform on which he sits, and, with the fingers pointing backward and the knees flexed, lifts the lower portion of the body gently backward until the lowest bony portion of the os sacrum is in contact with the front of the measuring standard. The back is then straightened until the back of the head comes into contact with the standard. It will be found that different persons require to bend the knees in different degrees in order to achieve this position. The head should be tilted neither up nor down and the eyes should look straight forward (Dreyer).

Simultaneously with their table of weights for stem-length, Dreyer and Hanson use a table of weights for chest-girth, and average together the two values obtained in order to make their prediction of the normal weight for the person measured.

37. Bornhardt, A.: St. Petersb. med. Wchnschr. 3:108 (March 22) 196 (April 3) (May 24) (June 5) 1886; id. 5:413 (Nov. 26) (Dec. 8) 1888.

38. Walker, E. W. A.: Proc. Roy. Soc., Lond. B89:157 (Jan. 1) 1916. 
For practical purposes their book of tables is cordially recommended as the best standard of weight available today. Evidence for this opinion will be given below.

The historical aspects of sitting-height and stem-length, and particularly the presumptive advantages of stem-length over stature, have been discussed by us previously. ${ }^{1}$

\section{NEW MATERIAL}

The subjects studied were 114 pupils at Mr. Robert W. Rivers' Open Air School for Boys, a country day school in Brookline, just outside this city. We are indebted for the opportunity to the principal and also to the school physician, Dr. Richard M. Smith.

From the latter's two recent studies ${ }^{39}$ on this establishment, it may be seen that our subjects represent a favored group, of American birth, good breeding and careful nurture.

Furthermore, the subnormal samples of boyhood discoverable, in process of betterment, in every school, have been in this study sifted out by means of the past history as obtained from parents, by the physical examination by the school doctor, by irregularity in school attendance and by general lack of stamina as observed from day to day by one of us who is in constant attendance as full-time school nurse.

Objection has been made to the use of well-to-do boys as criteria of the normal, on the ground that they are hot-house products (proteroplasia of Pfaundler ${ }^{40}$ ). It seems to us, however, that either they must be regarded as the finest specimens of young hopefuls in the nation, or else we might as well discard breeding and physical culture as degenerative factors!

Measurements.-The observations were made on the chest, sitting height and stem length by one of us; while the stature and weight were taken by the other of us on the youngest boys, and by a master on the other boys. Age was noted to the nearest rather than the last birthday. Weights were taken to the nearest pound, heights to the nearest quarter-inch and chest-girth at nipple level, first at rest, then at full inspiration and finally after expiration. The average of these last two chest measurements seems preferable to the resting girth, as will be shown elsewhere. All measurements are net.

The records were made on $5 \times 3$ inch cards. It was found convenient to use Library Bureau No. 30-5003, after ruling in three extra vertical lines to subdivide into four parts the space for chest-girth; and one extra line toward the right side of the third column from the left to

39. Smith, R. M.: Am. J. Dis. Child. 18:246 (Oct.) 1919; Am. J. Dis. Child. 20:115 (Aug.) 1920.

40. Pfaundler, M.: Ztschr. f. Kinderh. 14:1, 1916; 16:85, 1917. 
be used for sex. It would probably be more economical, and certainly more convenient, to have a card ruled to order by one of the card manufacturers, if one were planning to examine any large series of persons, say five hundred or more. A sample of the card as used is shown in Table 1.

TABLE 1. -Record Card of S. Gandi Male; Aged $7^{\text {at }}$

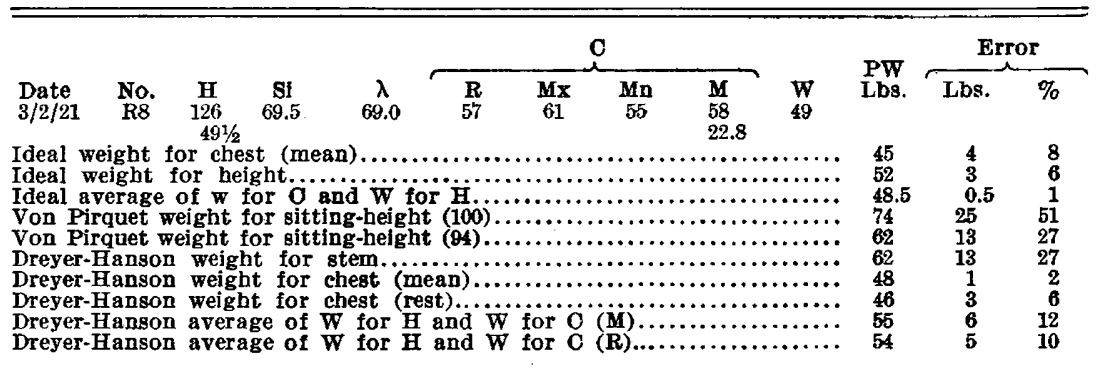

Abbreviations: No., serial number, e.g., Ricers Sehool case 8; H, height standing, in $\mathrm{cm}$. and inches; $\mathrm{Si}$, sitting-height, in $\mathrm{cm} . ; \quad \lambda$ stem length, to nearest 0.5 cm.; $C$, chest-girth at nipple level, in cm.; $\mathbf{R}$, chest-girth resting naturally; Mx, chest-girth after maximum expansion; Mn, chest-girth at minimum; M, chest-girth mean of last two measurements; W, weight observed; PW, predicted weight.

Method of Testing Standards.- In order now to ascertain which standard approaches most nearly to the observed weights of these healthy boys, we used the same simple though tedious procedure as in our earlier papers. In brief, we applied a given standard to a given boy, then took the difference between this theoretical weight and the subject's actual weight (which last was assumed to be the correct basis), and translated this difference in pounds from the observed weight into a percentage deviation or error. The formula was $(\mathrm{PW}-\mathrm{W}) \times 100 / \mathrm{W}$. For instance, if the predicted weight was 110 pounds and the weight 100 pounds, the difference of 10 pounds was recorded as a 10 per cent. prediction error. Calculation of this percentage is clearly necessary since, for example, the above 10 pounds absolute divergence is much less significant than it would be in the case of a child of 50 pounds, when the prediction error would be 20 per cent. By summing the errors thus calculated, and dividing through by the number of subjects measured we secured the average error of the prediction standard A. Standards B, C, etc., were similarly tested in turn. ${ }^{42}$

41. The name, sex and age belong in the third, fourth and fifth columns of the card, but are here printed above in order to permit clearer display of the other columns.

42. Since this paper was submitted there have been printed several interesting discussions of Pirquet's method: Faber, H. K.: J. A. M. A. 77:1837 (Dec. 3) 1921. Carter, W. E.: J. A. M. A. 77:1911 (Dec. 10) 1921. Bardeen, C. R.: J. A. M. A. 77:1988 (Dec. 17) 1921. Weymouth, F. W.: J. A. M. A. 77:2080 (Dec. 24) 1921 . 


\section{RESULTS OF TESTS}

The numerical results are shown in Table 2 in the shape of various constants recommended by statisticians.

Our inferences from these facts are submitted, with the realization that they might be interpreted differently by those familiar with biometric principles.

1. The Ideal Tables, tentatively proposed by us elsewhere, show here the smallest average error, only 4.6 per cent.

2. At the same time, Dreyer and Hanson's tables show an accuracy only slightly less for children (mean error 4.8 per cent.), and for adult men are plainly the best standard available today (error 4.5 per cent., as published in an earlier article ${ }^{1}$ ).

3. Dreyer and Hanson's tables also exhibit the smallest standard deviation of any method.

4. Also Dreyer and Hanson's range of error is the smallest of any.

TABle 2.-Error in Prediction of Weight by Different Standards as Tested on 114 Rivers' School Boys

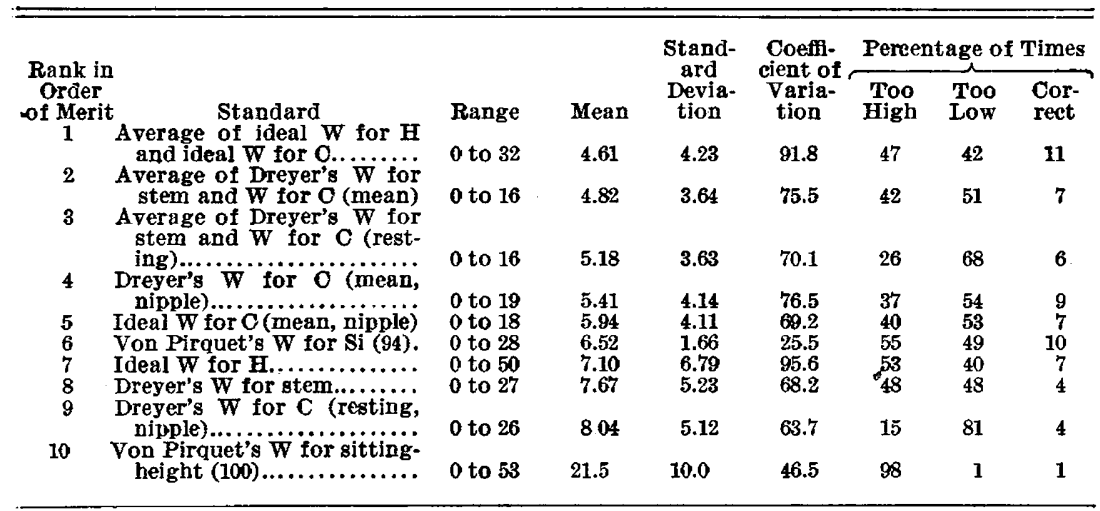

* The name, sex and age belong in the third, fourth and fifth columns of the card, but are here printed above in order to permit elearer display of the otber columns.

5. According to the coefficient of variability (C.V.), Dreyer and Hanson's tables excel our Ideal Tables, but the use of this criterion (C.V.) alone seems misleading, since the lowest C.V. of all pertains to Pirquet's formula, which we regard as the least useful of all those here analyzed. The difference in the results with Pirquet's formula is notable, according to whether one starts from an arbitrary index of 100 or 94 .

6. Finally, as to theory, Dreyer's tables are said to be derived from a formula, and therefore represent a law rather than simply empiricism. This should mean that Dreyer's formula could be applied to individuals whose measurements lie outside the range of Dreyer and 
Hanson's tables. It so happens, as detailed elsewhere, ${ }^{1}$ that we have personally been unable to operate Dreyer's formula in such a way as to secure the values given in his tables, but this difficulty does not vitiate the value of the latter. Although we have not been able to use the formula for children outside the range of the tables, a graph made from the tables could probably be extended to give values for such small children.

\section{CONCLUSIONS}

Although our Ideal Tables seem the most exact by a slight margin, it is quite probable that for general use, on adults and children alike, the most satisfactory method hitherto proposed for estimating the correct weight of a normal person is the combination of Dreyer and Hanson's weight-for-stem and weight-for chest tables, with the modifcation that the chest-girth used be what we have called the mean girth rather than the resting girth advocated by Dreyer. 